\title{
Practitioners' opinions on the presentation of ocu- lar pathology and ametropia in patients wearing ready-made reading spectacles
}

\author{
KC Phillips* and PC Clarke-Farr**
}

Department of Ophthalmic Sciences, Faculty of Health and Wellness Sciences, Cape Peninsula University of Technology, P.O. Box 652, Cape Town, 8000 South Africa

*<kcphil@iafrica.com>

**<clarkefarrp@cput.ac.za>

Received 17 June 2008; revised version accepted 30 September 2008

\section{Abstract}

This paper presents the findings of a study to determine optometrists' opinions on the presentation of ocular pathology and ametropia in patients wearing ready-made reading spectacles. Ninety-seven optometrists completed a questionnaire pertaining to ametropia and ocular diseases among these patients. The questionnaire contained information regarding patient demographics, ocular pathology, ocular ametropia and the regulatory and public health aspects of ready-made readers.

Ninety-five percent of respondents stated that they had seen patients with ready-made readers in their practice and $62 \%$ of these stated that they had found the presence of ocular pathology in these patients. The pathologies most commonly reported as seen by practitioners were dry eye $(86 \%$ of practitioners), cataracts $(80 \%)$ and diabetic retinopathy (54\%). In addition, $39 \%$ of practitioners reported seeing patients with anisometropia. The majority of practitioners $(71 \%)$ stated that they sold readymade readers in their practice. Sixty-three percent of practitioners indicated that they would be pre- pared to offer a service whereby a reduced consultation fee and a pair of ready-made readers could be incorporated into an indigent "package". An overwhelming $88 \%$ of the practitioners felt that the sale of ready-made readers should be more regulated and $74 \%$ of practitioners felt that the Professional Board for Optometry and Dispensing Opticians should be responsible for monitoring their sale.

The research suggests that wearers of readymade readers should be screened for ocular pathology, reduced visual acuity and amblyopia. Current regulations should be tightened and a public awareness education campaign should be initiated. The use of ready-made reading spectacles, in deference to an eye examination by an optometrist, appears to be largely as a result of the perceived costs of private practice combined with ignorance and apathy.

\section{Key words}

Ametropia, anisometropia, cataract, diabetic retinopathy, glaucoma, hypertensive retinopathy, ocular pathology, presbyopia, ready-made readers.

* MCOptom (UK), Part-time Lecturer in Department of Ophthalmic Sciences, Faculty of Health and Wellness Sciences, Cape Peninsula University of Technology

** PhD (UFS), Head: Department of Ophthalmic Sciences, Faculty of Health and Wellness Sciences, Cape Peninsula University of Technology 


\section{Introduction}

This study originated when the first author examined a patient who had been referred for an eye screening by the local Traffic Department after having failed the standard driver's vision test. He was a 53 year-old habitual wearer of ready-made readers and had never had an eye examination. On examination, the patient was found to have significant glaucomatous cupping (Figure 1), raised intra-ocular pressures (IOP's) and uncorrected visual acuities of Right 6/48 and Left $6 / 36$.

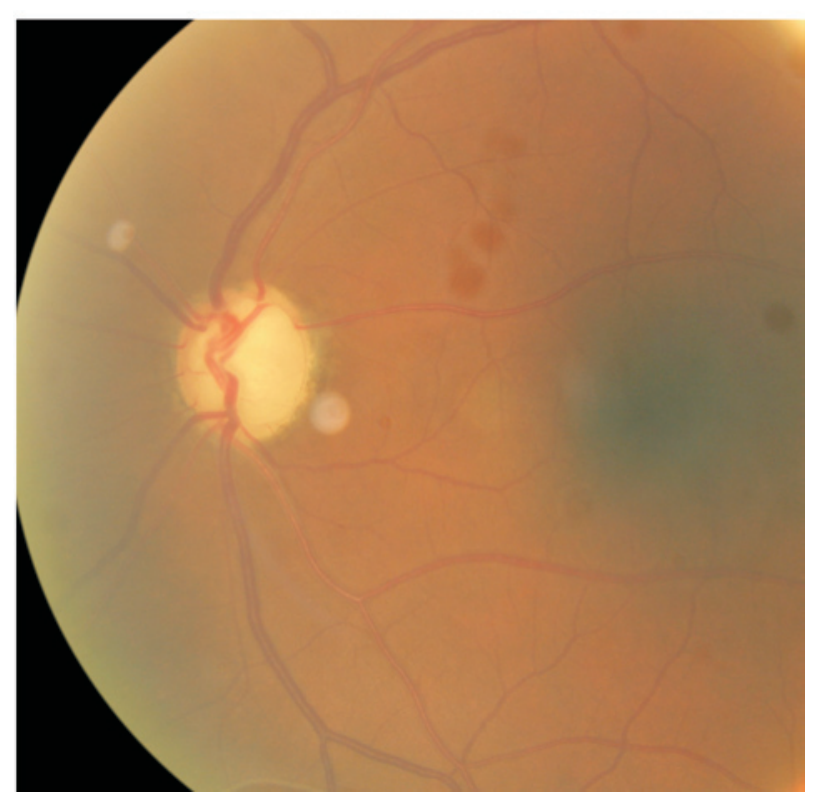

Figure 1. Suspected glaucoma in 53 year-old habitual wearer of ready-made readers

The Professional Board for Optometry and Dispensing Opticians (PBODO) of the Health Professionals Council of South Africa (HPCSA) has for some time monitored the provision of ready-made readers. This culminated in the promulgation of regulations in the Government Gazette ${ }^{1}$ regarding the sale of ready-made reading spectacles in September 2006. These regulations require that these spectacles may not exceed the power range of 1-3 D, are moulded lenses of equal powers in the right and left eye and be accompanied by a warning that: "Diseases causing blindness can only be detected by having a regular, professional eye examination. These reading glasses are only for short term use by persons over the age of 40 years and are not suitable for driving purposes." 1

Regulation of ready-made reading glasses is not only a South African problem. In Italy, the Ministry for $\mathrm{Health}^{2}$ has specified that ready-made readers need to adhere to certain vertical prismatic tolerances (vertical prismatic effect may not exceed 0.33 prism dioptres) as well as specifying that interpupilliary distances must be within 58 to 64 millimetres which must be displayed in the form of a sticker on the lenses along with the warning that the spectacles are not to be used for driving. In 2003, the European Parliament ${ }^{3}$ debated the issue of the public buying inappropriate ready-made readers and was likened to people taking too large doses of paracetamol whereby the natural instinct is for people to pick a stronger lens just as people take extra paracetamol for a headache. This resulted in patients frequently exceeding the recommended dose. The fact that people frequently purchased a stronger prescription than they required led the European Parliament ${ }^{3}$ to conclude that the use of such spectacles led to asthenopia and that a warning must be issued so that people were aware of the dangers. The European Parliament ${ }^{3}$ emphasised that the onus was on the Government to highlight this issue. They also pointed out that ready-made readers were not suitable for children and specifically that children under seven years of age should not use ready-made readers because there is a danger of permanently damaging their sight. In direct contrast, the Government of Jersey ${ }^{4}$ has legislated that anyone over the age of 16 years can purchase ready-made readers, without restriction.

In preparation for this study, the authors visited three of the major retail outlets (pharmacy, household appliance and book store) selling ready-made reading spectacles in the Western Cape. None of these outlets displayed any form of warning and in the case of two retailers, powers of $+3.5 \mathrm{D}$ were available for sale. This highlighted the fact that current regulations ${ }^{1}$ in South Africa are not being adhered to closely enough. Anecdotal evidence has for some time suggested that significant numbers of patients wearing ready-made readers are found to have various ocular pathologies and ametropias, including anisometropia, when attending optometric practices. Such conditions, in addition to causing ocular discomfort and fatigue, have the potential to lead to severe and irreversible visual impairment if not detected and treated at an early stage.

It may be expected that most wearers of readymade readers start using them from the age of 45 years when experiencing the effects of presbyopia ${ }^{5,6}$. There is also the potential that younger uncorrected 
hyperopes would be users before the age of 40 . The concern in these patients in particular is that many of them might never have had any form of eye examination. The perception in the general public may also be that the need for reading glasses is a normal process of ageing and thereby neglect a comprehensive ocular examination.

Presbyopia, although not conforming to the strict classical definition of refractive error ${ }^{5}$, may still be considered to be a refractive disorder. This implies a deviation from the normal in terms of near vision requiring remedial measures in the form of a near-image focussing device, commonly referred to as reading spectacles. Whilst the accommodating, or nearfocusing ability of the eye reduces steadily with age, presbyopia typically occurs after the age of 40 years ${ }^{6}$ with symptoms of blurring of near print or objects. In the normal course of events, patients experiencing these symptoms would seek expert advice on how best to overcome them. This is, however, often not the case and many individuals continue to suffer from the symptoms or seek relief by means of an inexpensive and speedy alternative in the form of ready-made reading spectacles. These spectacles can either relieve the symptoms or exacerbate them in which case they are discarded, or offer temporary relief with a possibility of masking some ocular disease. They may also offer some relief but often may not be tolerated for very long without discomfort. Possible reasons for non-tolerance of ready-made reading spectacles may include incorrect prescription for the patient's eyes, incorrect centration of the lenses leading to prismatic imbalance between the two eyes and aberrations or distortions present in the lenses.

It is not surprising that any reference to ready-made reading glasses elicits some concern from eye care professionals about the possible presence of undiagnosed ocular disease. Reidy et $a l^{7}$ are of the opinion that untreated visual impairment and eye disorders affect a substantial proportion of people aged 65 years and older. In this North London-based study $21 \%$ of those examined had V/A less than $6 / 60$ in one or both eyes. The prevalence of cataract causing visual impairment was $30 \%$ and $88 \%$ of these people were not in touch with the eye care services. Prevalence of vision-impairing age-related macular degeneration was $8 \%$ and of glaucoma (confirmed cases) was $3 \%$. It was furthermore suggested by Reidy et $a l^{7}$ that three quarters of the people with definite glaucoma had not presented to the eye services, which is of particular concern. Based on these statistics, it may be inferred that citizens below the age of 65 years, although not having the same prevalence of eye disorders, could also be at risk, particularly those older than 40 who are presbyopic or approaching presbyopia. Reidy et $a l^{7}$ suggested that, whilst their data was not adequate to reliably estimate the extent of visual impairment and serious eye disease in metropolitan areas in Britain, data from north London showed that $30 \%$ of a sample of the population aged 65 or older were visually impaired in both eyes. Moreover, more than $72 \%$ of the bilateral visual impairment was potentially remediable by surgery or spectacles.

In the above study, the authors conclude that eye problems were more prevalent in people living in relatively underprivileged areas. Mason ${ }^{8}$ argues that nutritional intake can delay the development of cataract and the researchers for the Korean Medical Database ${ }^{9}$ suggest that imbalance of nutrient intake has been related to ametropia. Many South Africans live under poor socio-economic conditions which, together with local climatic conditions, may suggest that cataract might in fact occur earlier. This is particularly relevant considering the known contribution of ultraviolet light ${ }^{10}$ towards cataract formation and the climate to which the South African population is exposed.

Griffith $^{11}$ reports that in his screening clinic, patients had cataracts or subtle pigmentary changes at the macula, yet had good vision and were unaware of any problem with their eyes. Fraser et al ${ }^{12}$ maintain that demographic area and individual level of deprivation were both associated with late presentation of glaucoma and also emphasize that late presentation for eye examination is an important risk factor for developing subsequent visual impairment and blindness. According to these authors poverty also seems to play an important role in the development of blindness as they conclude that deprived groups seem to be at greater risk of going blind from glaucoma that non-deprived groups. It would appear then from their research that poverty may be associated with more aggressive disease as well as later presentation for examination and treatment.

According to the figures quoted by the Society for Endocrinology, Metabolism and Diabetes of South Africa (SEMDSA) ${ }^{15}$, Type II diabetes is rapidly assuming epidemic proportions in South Africa, being most prevalent among those patients in the 65 and 
above age group in urban Cape Town. These statistics indicate that $29 \%$ of those over 65 , who are all presbyopic, have Type II diabetes. Being presbyopic, most of these patients would need some form of correction for reading, and, if one takes into account the study in North London by Reidy et $a l^{7}$ where $21 \%$ of the population over 65 had V/A of less than 6/60, it might be assumed a significant proportion in the SEMDSA statistics have a poor distance acuity. If such patients rely only on ready-made readers without proper eye examination, there is a great potential for diabetic retinopathy to progress to an advanced stage before treatment is initiated.

With regard to refractive error and the prevalence of amblyopia, this would be of particular concern due to its contribution towards preventable blindness. Karti ${ }^{17}$ estimates the prevalence of amblyopia resulting from uncorrected ametropia to be in the region of $2-4 \%$ of the population of Kathmandu and is reported to be one of the top three causes of monocular vision loss in the adult age group. This represents a sizeable proportion of the economically active population and consequently has an important negative socio-economic effect. These figures can certainly be applied to the South African context in order to predict the potential risks to the population who do not undergo appropriate eye examinations.

In terms of asthenopia, du Toit et al ${ }^{18}$ conclude that most spectacle wearers would comfortably tolerate $\leq 0.5 \mathrm{pd}$ vertical, $\leq 1.0 \mathrm{pd}$ base out, or $\leq 1.0 \mathrm{pd}$ base in induced prism. These authors formulated guidelines to the maximum interpupillary distance/optical center distance disparities likely to be comfortably tolerated with varying spectacle powers and recommend that powers up to $1.5 \mathrm{D}$ are unlikely to have sufficient lens decentration to cause discomfort. However in ready-made reading spectacles, powers of up to +3.5 $\mathrm{D}$ dioptres are encountered and an interpupilliary discrepancy of just 2 millimetres per eye in these would induce an uncomfortable prismatic effect of $1.4 \mathrm{pd}$, in excess of the findings of du Toit et al ${ }^{18}$. Therefore any patient whose interpupillary distance does not correspond to the optical centration of the ready-made readers would be at risk of experiencing significant prismatic effects. This, as well as any uncorrected astigmatism or anisometropia would almost certainly lead to asthenopia or eye-strain ${ }^{6}$.

In the South African context, the average cost $\mathrm{t}^{19}$ of an optometric consultation and spectacles in 2006 was R1165 but the visits to optometrists were reduced from 296 per 1000 to 223 per 1000 of the population. This cost factor is significant in a price-sensitive society like South Africa, where there is a paucity of public service outlets for eye care with the inevitable consequence that the underprivileged become even more under-serviced. It has long been the aim of Optometry in South Africa to become part of the Primary Care health team ${ }^{20}$. Indeed, one of the primary areas of focus of the 1999-2003 PBODO was the furtherance of this idea and, to this end, the Certificate for Advanced Study (CAS) was implemented to improve the skills of South African optometrists in, especially, the diagnosis of many ocular diseases and abnormalities $^{20}$. This point is relevant because optometrists are now able to diagnose far more readily than before and as a result more previously undetected pathologies will be diagnosed. This is indeed so in other parts of the world also such as the United States where the role of the optometrist has expanded greatly in terms of primary health care ${ }^{21}$.

\section{Methodology}

A questionnaire which aimed to determine practitioners' opinions on the prevalence of ocular pathology and ametropia in patients wearing ready-made reading glasses was used. It contained 25 questions with the first six questions dealing with the demographics of the practice concerned and the patients attending that practice. These questions also reflected the Province of the practitioner, whether they worked independently or as part of a group or franchise and whether they worked in a shopping mall, a free standing building or from a house. Four questions dealt with the reasons that the patients wore these spectacles and the reason for the consultation. Six questions related to the ocular pathologies seen in such patients and three questions referred to ametropia and anisometropia. Two questions determined whether practitioners provided ready-made readers in their practice and their opinions on providing affordable eye care. The remaining four questions dealt with the regulatory aspects and the roles of responsibility for pathologies which may go undetected in such patients. Prior to the distribution of the questionnaire, a pilot study was conducted with five optometrists to ensure that the questionnaire was clear and unambiguous. It was the aim of the survey to complete all questionnaires electronically.

Prior ethical approval was obtained from the Re- 
search Ethics Committee of the Faculty of Health and Wellness Sciences of the Cape Peninsula University of Technology. A request was made to the South African Optometric Association (SAOA) for their help with the distribution of the questionnaires. This was granted and the questionnaires were sent to all members of the SAOA via e-mail. The questionnaires were completed anonymously by optometrists who detailed their experience of the subject in their practices and concerned their reporting on all habitual wearers of ready-made reading spectacles presenting for an eye examination or screening over the past 12 months and returned to the authors electronically. The target population included optometrists from across South Africa. There were no inclusion or exclusion criteria other than that the respondent was a registered optometrist and willing to participate in the study. The data obtained from the questionnaires was captured and analysed using the Statistical Package for the Social Sciences (SPSS) according to the coding system set up for the questionnaire. The results were analysed according to five main themes, and inferences drawn were based on the overall trends observed from the results. The results are presented according to demographic characteristics, the prevalence of ready-made readers encountered in practice, the prevalence of pathology, the prevalence of ametropia and the regulatory and public health aspects. The last section of the questionnaire dealt with whether practitioners made ready-made readers available to their patients. It also aimed to elicit their opinions on how the sale of readymade readers should be regulated and who should be responsible for the undiagnosed pathology developing in such patients. The full questionnaire and table of results is not included in this article but is available upon request.

\section{Results}

The number of respondents, the frequency and the percentage of the respondents was calculated for each question. The total number of practitioners responding to the questionnaire was 97.

\section{Demographic characteristics}

The highest percentage of respondents was from Gauteng (32\%) followed by the Western Cape (26\%) and Kwa-Zulu Natal (14\%). In terms of the area of the practice, most were located in urban areas $(63 \%)$ whilst $30 \%$ of respondents stated that they were locat- ed in a mixed area (suburban - outside the major city demarcation). Only $7 \%$ of respondents had a practice located in a rural area. Forty-nine percent of respondents had their practice located in a retail shopping mall with $32 \%$ practicing in an independent freestanding practice. Eighteen percent of practitioners were located either in a house or their own premises. The vast majority (79\%) of respondents practiced from an independent solo practice or partnership whilst 19\% were in a franchise. Only one practitioner stated that he/she was in the public health sector. The survey found that $32 \%$ practices had patients who were described as generally affluent whilst $10 \%$ of practices had predominantly less affluent patients attending. The majority (58\%) of practices, however, stated that their patients were of mixed economic status.

\section{Prevalence of ready-made readers}

Most practitioners surveyed (95\%) stated that they had seen patients with ready-made readers. Seventynine percent of practitioners reported that the patients used the ready-made readers primarily for reading at near, but interestingly $19 \%$ of practitioners stated that they had seen patients wearing readers for both distance and near vision. One practitioner reported having a patient using the readers for distance vision. No clear pattern emerged as to the reason why the patients were attending the eye examination, although $17 \%$ of practitioners stated that patients complained of headaches, $8 \%$ had failed their driver's vision test and $7 \%$ reported that these patients complained of poor vision. Many (67\%) respondents stated that their patients with ready-made readers were attending for their first eye examination.

\section{Prevalence of pathology}

A particularly significant finding was that $62 \%$ of practitioners surveyed stated that they had found the presence of some form of ocular pathology in their patients. The questionnaire asked practitioners to state whether they had encountered any of the listed ocular diseases in their patients who presented wearing ready-made readers. A summary of the practitioners responses on the conditions that they have encountered in their patients is presented in Table 1. 
Table 1: Percentage of practitioners encountering pathology

\begin{tabular}{|l|l|}
\hline Patients with hypertensive retinopathy & $39 \%$ \\
\hline Patients with diabetic retinopathy & $54 \%$ \\
\hline Patients with glaucomatous changes & $43 \%$ \\
\hline Patients with cataract & $80 \%$ \\
\hline Patients with dry eye & $86 \%$ \\
\hline
\end{tabular}

The questionnaire then asked the practitioners to state in what percentage of cases was there significant pathology in patients wearing ready-made readers. The opinions of practitioners with respect to the overall prevalence of pathology they encountered are shown in Table 2.

Table 2: Percentage of cases seen with pathology

\begin{tabular}{|c|c|c|}
\hline $\begin{array}{l}\text { Percentage of cases } \\
\text { seen with pathology }\end{array}$ & Frequency & Percent \\
\hline 0 & 6 & 6.2 \\
\hline 10 & 44 & 45.4 \\
\hline 25 & 24 & 24.7 \\
\hline 50 & 16 & 16.5 \\
\hline 75 & 5 & 5.2 \\
\hline Not answered & 2 & 2.1 \\
\hline
\end{tabular}

\section{Prevalence of ametropia}

The design of the questionnaire also aimed to elicit whether patients wearing ready-made readers had significant refractive errors which could possibly impact on their function. The results of this aspect of the study is shown in Table 3. Thirty-six percent of the practitioners surveyed estimated that $75 \%$ of their patients had significant refractive error, $20 \%$ of the practitioners estimated that $50 \%$ of their patients wearing ready-made reading spectacles had refractive error and only approximately $20 \%$ of practitioners reported $10 \%$ or less of their patients having refractive error. It was also found that $39 \%$ of practitioners found patients with anisometropia who wore readymade readers.
Table 3: Percentage of cases with ametropia

\begin{tabular}{|l|l|l|}
\hline $\begin{array}{l}\text { Percentage of cases with } \\
\text { ametropia }\end{array}$ & Frequency & Percent \\
\hline 0 & 4 & 4.1 \\
\hline 10 & 15 & 15.5 \\
\hline 25 & 14 & 14.4 \\
\hline 50 & 20 & 21.3 \\
\hline 75 & 35 & 37.2 \\
\hline 100 & 6 & 6.4 \\
\hline Not answered & 3 & 3.1 \\
\hline
\end{tabular}

Regulatory and public health aspects

As far as regulatory and Public Health aspects were concerned, the majority of practitioners $(71 \%)$ stated that they sold ready-made readers in their practice. Another 63\% reported that they would be prepared to offer a service whereby a reduced consultation fee and a pair of ready-made readers is incorporated into an indigent "package". An overwhelming $88 \%$ of the practitioners felt that the sale of ready-made readers should be more regulated. When questioned in what form the regulation should take, $44 \%$ of respondents believed that ready-made readers should only be sold by eye care practitioners and $29 \%$ stated that they should only be sold on prescription (Table 4 and Figure 2.)

\begin{tabular}{|l|c|c|}
\hline $\begin{array}{l}\text { Opinion regarding the } \\
\text { regulation of readymade } \\
\text { readers }\end{array}$ & Frequency & Percent \\
\hline Do not regulate & 7 & 7.2 \\
\hline $\begin{array}{l}\text { May be sold only by eye } \\
\text { care practitioners }\end{array}$ & 43 & 44.3 \\
\hline $\begin{array}{l}\text { May only be sold by phar- } \\
\text { macies }\end{array}$ & 2 & 2.1 \\
\hline Only sold on prescription & 28 & 28.9 \\
\hline $\begin{array}{l}\text { Current regulations are } \\
\text { good, need better control }\end{array}$ & 16 & 16.5 \\
\hline Not answered & 1 & 1 \\
\hline
\end{tabular}




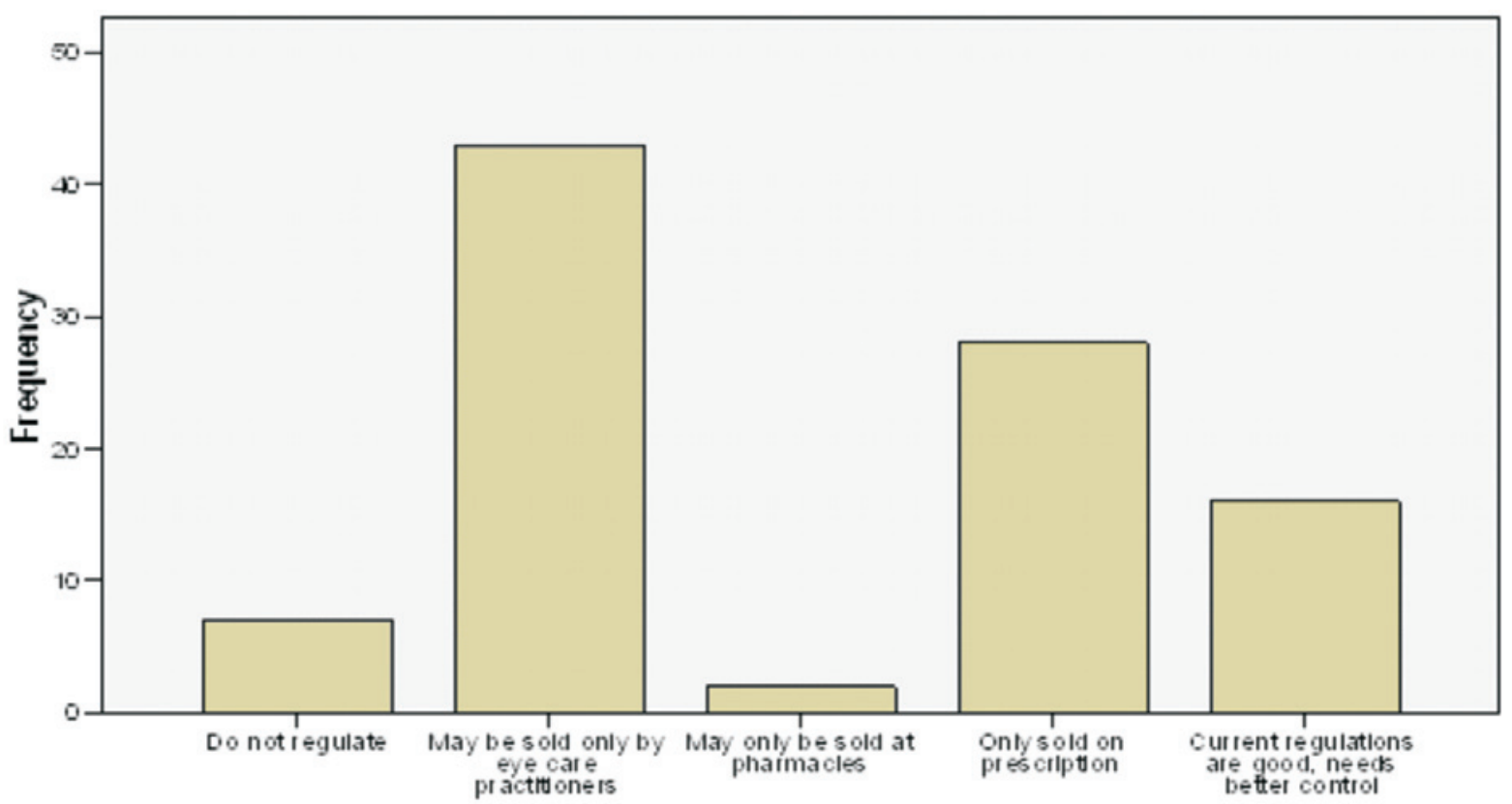

Figure 2: Opinion regarding the regulation of ready-made readers

In terms of who should be responsibility for policing the sale of readers, the majority $(74 \%)$ of practitioners felt that the PBODO should be responsible (Figure 3).

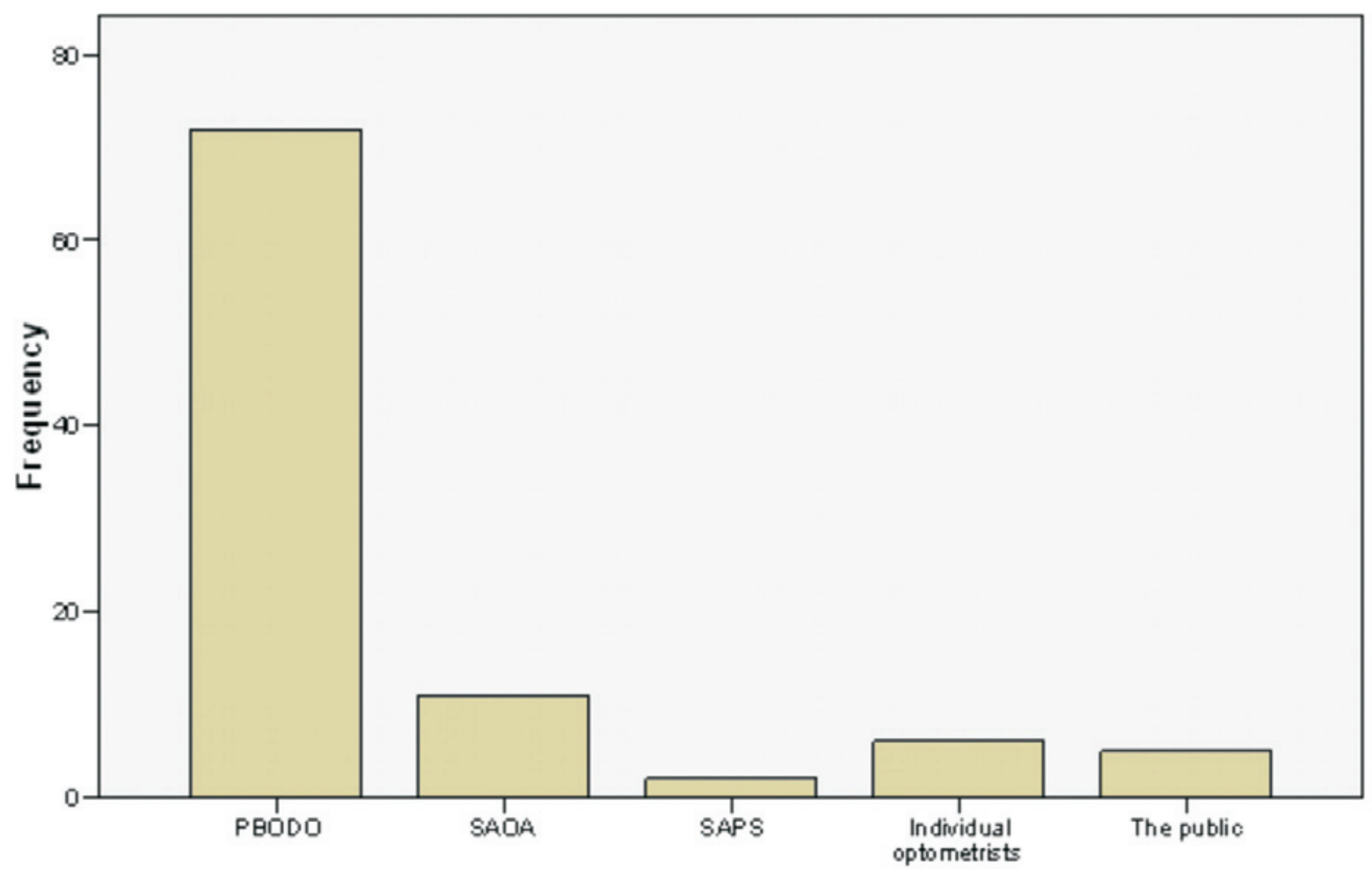

Figure 3: Responsibility for policing the sale of ready-made readers

However, when considering who should bear responsibility for the untreated pathology occurring in these patients, $40 \%$ of practitioners were of the opinion that it should be the patients themselves. About $24 \%$ of practitioners felt that the suppliers of the readers should bear that responsibility and $18 \%$ felt that the PBODO should be responsible for this. This is illustrated graphically in Figure 4. 


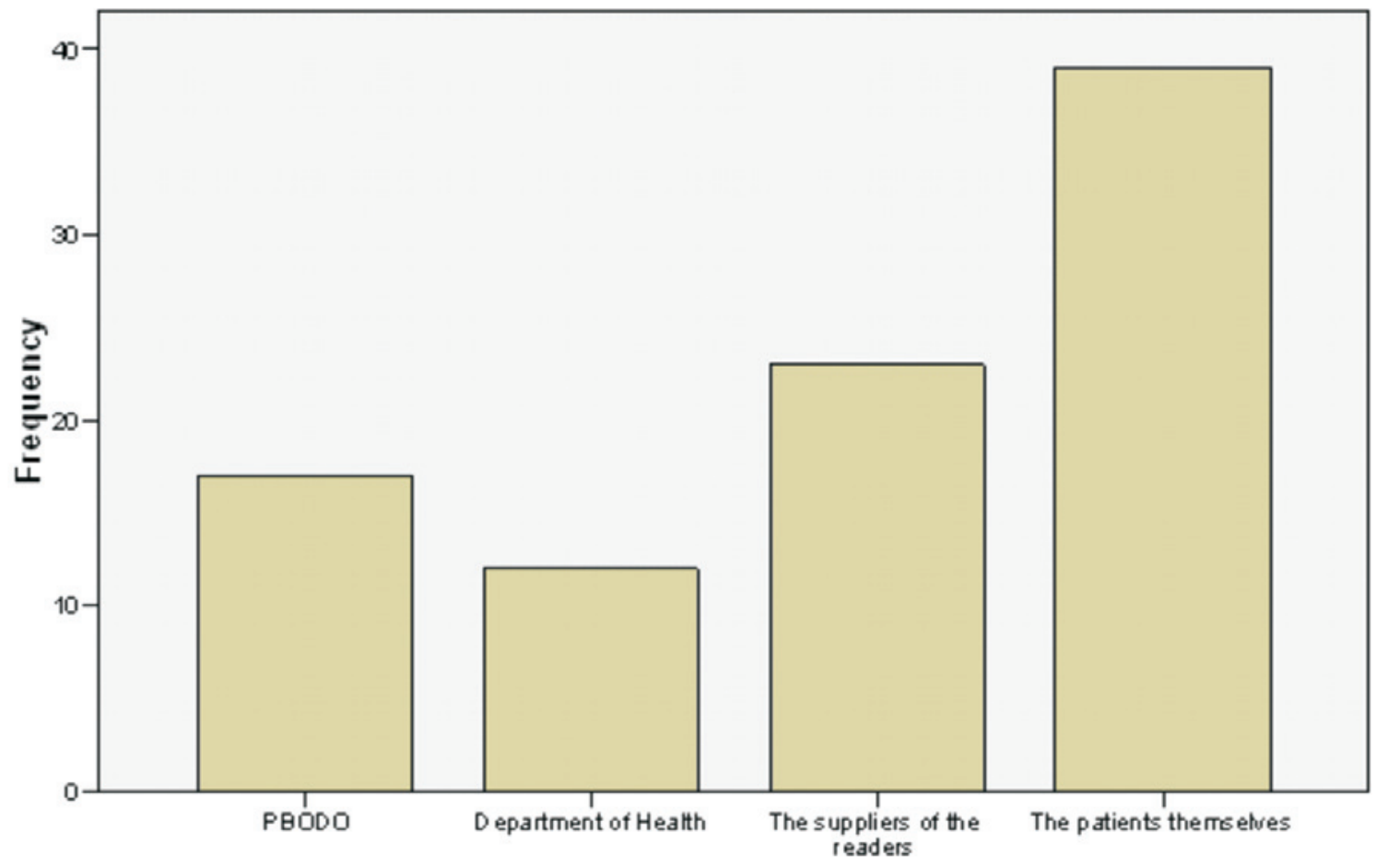

Figure 4: Responsibility for untreated pathology by ready-made readers

\section{Discussion}

The majority of the respondents were located in urban areas $(63 \%)$, while only $7 \%$ practiced in a rural setting. This is significant as it appears to confirm the reports $^{26}$ that those living in rural areas have reduced access to eye care services or ophthalmologists. Furthermore, with reference to socio-economic status, only $10 \%$ of respondents reported that their patient base was predominantly poor while $32 \%$ of practitioners had patients who were generally affluent. This raises the question of why affluent patients resort to ready-made readers when they possess the means to obtain proper correction? Is it because of convenience, apathy or ignorance of the possible ocular pathologies that may exist in the eyes?

With regard to patients presenting with ready-made readers, $65 \%$ of practitioners reported that it was their patients' first eye examination. When asked why they attended, $17 \%$ of practitioners reported that patients gave headaches as the reason. From the results it appears that some of the patients consulted because of asthenopia or visual problems. The results also show that the majority of patients attending the optometric practices had significant refractive errors and almost $40 \%$ of respondents found significant anisometropia in patients wearing these readers. This is noteworthy, given the reporting of headaches as the reason for such patients attending the optometric practices.

The fact that $62 \%$ of practitioners reported that they had found some ocular pathology in their patients wearing ready-made readers should be cause for concern for legislators and public health planners. The definition of what constitutes significant pathology seems to be blurred in many instances. Some respondents reported that they had seen no patients with significant pathology, yet $80 \%$ of these said that they had seen patients with cataract and dry eye. Glaucoma was commonly seen with $43 \%$ of respondents reporting that they had noticed glaucomatous changes in ready-made reader patients they had examined. It can be argued that these, as well as patients having diabetic retinopathy (reported by $54 \%$ of respondents) and hypertensive retinopathy (39\%), are conditions that are found in the everyday population as a whole. However, these patients could receive appropriate management and education about their ocular and systemic conditions, providing significant health benefits as well as preventing avoidable blindness. Reported cases of potentially blinding diseases such as diabetic and hypertensive retinopathy emphasize the role that optometrists can play in educating, recognizing, managing and referring patients on systemic health issues - an option that is not available in retail outlets selling ready-made readers. The possible ex- 
ception being pharmacy; although pharmacists do not use ophthalmoscopes and are generally not trained to detect and diagnose ocular disease.

Importantly, $80 \%$ of the optometrists had seen patients within the target group showing signs of cataracts. Dry eye was also commonly reported $(86 \%)$ by the practitioners. Again, advice, counseling and management of these patients falls clearly within the realm of the optometrist and significant relief can be provided to alleviate this condition. The question arises whether those patients with ocular pathology, such as cataracts, did not attend the eye services because of costs (including transport), unwillingness or of ignorance of their condition. It is the experience of the authors that apathy abates when necessity arrives and those individuals seeking a renewal of their driving license are sooner rather than later going to seek assistance. Sadly, in the case of glaucoma this is often too late.

This research did not take into account the cost or perceived price difference of ready-made readers at optometric practices versus retail outlets. Even though $71 \%$ of practitioners indicated that they sold them in their practices, this perception may be the reason why fewer people see optometrists than buy ready-made reading spectacles over the counter. The majority of optometrists, however, indicated that they would be prepared to offer a service whereby a reduced consultation fee would be charged together with the sale of ready-made readers to ensure that poorer patients still receive quality eye care. This, however, raises the question of how one could justify charging a lower rate for a patient who wants ready-made readers and a higher rate for someone who desires sophisticated Free Form Progressive Addition Lenses? The answer here could be a "means test" similar to that done with the State provision of public healthcare. In such cases, patients of limited financial means, upon demonstration of proof of income, would be eligible for the lower rate package.

The majority of optometrists $(88 \%)$ felt that the current regulations were inadequate and that more regulation is needed. Almost a third of practitioners felt that ready-made readers should be sold on prescription only and $45 \%$ felt that they should only be sold in optical practices. It appears that the current regulations are not being enforced and so to expect that stricter control would work is perhaps impractical given the volume of ready-made readers being sold. Almost $17 \%$ of optometrists reported that the current regulations were satisfactory but needed better control.

Nearly $75 \%$ of respondents felt that the PBODO should be responsible for the policing of the sale of ready-made readers since the role of the HPCSA has been defined as to "guide the profession and to protect the public" 25 . Many optometrists (40\%), however, believed that the responsibility for untreated pathology lay with the purchasers themselves, closely followed by the suppliers of the ready-made readers. It is the authors' view that those selling ready-made reading spectacles without clearly advising purchasers of the need for regular eye examinations should be held accountable for undetected pathology.

\section{Conclusion and Recommendations}

It is evident from the results of this study that many of the wearers of ready-made readers have some degree of ocular pathology or ametropia or both. It is therefore imperative that those wishing to purchase these items should be screened for ocular pathology. It is accepted that economic factors will hold sway in respect of ametropia but pathology has great public health implications. Clearly the appropriate use of ready-made readers, without comprehensive eye and vision examinations, is a public health issue. A major public awareness campaign highlighting the possible dangers of self-correction using such readers needs to be launched involving all stakeholders such as the Department of Health, the SAOA, the PBODO, the ophthalmic suppliers and Ophthalmology. In order to facilitate adherence to the regulations as promulgated, it might be prudent for the PBODO to implement or adopt the Italian ${ }^{11}$ model of displaying a largely printed sign at the point of sale of ready-made readers, proclaiming that they are not suitable for driving. The size of the print is important as it should be large enough to be read without the help of spectacles. An indication of interpupilliary distance should also be provided on the ready-made readers as induced prismatic effects may contribute to asthenopia.

Weale ${ }^{22}$ states that the global picture reveals a systematic rise in the prevalence of anisometropia with age whereby there is a significant positive shape of $1 \%$ for every seven years. This indicates that there exists a significant body of people in all population groups who have ametropia or systemic and ophthalmic pathologies, much of which is undiagnosed. Op- 
tometry is ideally suited to play a pivotal role in the identification and thus the treatment of ametropia and these pathologies. A possible solution would be for South Africa to adopt a model similar to that of Australia $^{23}$ where every citizen is entitled to an optometric consultation every two years, funded by the State. The public health benefits even for systemic disease management and prevention would be enormous and those wishing to purchase ready-made readers would at least have been screened for pathology and the cost of consultations could be reduced due to the volume of work being done.

Finally, it is worth noting that Luo et $a l^{24}$ found that presbyopia corrected with glasses is associated with a nominal decrease in quality of life. Unfortunately, asthenopia and silent or undetected pathology would serve to worsen this. The fact that individuals choose to make use of ready-made reading spectacles in deference to having their eyes examined appears to be largely a result of poverty (in South Africa) combined with ignorance and apathy. A significant limitation of this study is the fact that it is based on practitioners perspectives of patients they had seen in practice which is not necessarily the true prevalence in all patients wearing ready-made readers. However, the opinions and perspectives expressed can provide a meaningful insight into the current situation. Given the volume of ready-made reader availability, this sample represents merely a fraction of the widespread use of these items and further research would be needed to determine the quantity of ready-made readers sold in South Africa and the prevalence of pathology and ametropia in a representative sample of the above. This study does, however, lay the foundations for future research into the exact prevalence of ocular disease in such patients.

\section{Acknowledgements}

The authors would like to thank the following for their help with this research: Mr. Harry Rosen and the SAOA, in conjunction with Eyesite, and Faldelah Ryklief for the distribution of the questionnaires; Ms Anthea Pinto for her help in capturing the data on SPSS; the practitioners who responded to the survey and to the Cape Peninsula University of Technology for the use of their resources.

\section{References}

1. RSA (Republic of South Africa). South African Government Gazette 8 September 2006 No 29171 Volume 495. Cape Town: Government Printer.

2. Minister for Health (Italy) (2007). Amendments to the interministerial decrees of 23 July 1998 and 21 December 1999 on the public sale of custom-made spectacles and lenses. http://www.bsmi.gov.tw/upload/b0d/TBTENQ/Member/ Italy/ITA-2Relevant.htm_Accessed 6 January 2008

3. European Parliament (2003) Debate on ready-made reading spectacles Opticians (Amendment) Bill 2002: Report and Final Stages. http://historical-debates.oireachtas.ie/D/0568/ D.0568.200306180021.html_Accessed 6 January 2008 The Government of Jersey (THE STATES). 21st May 2002.

4. Optical appliances: sale of 'ready readers' - P.55/2002. http://www.statesassembly.gov.je/documents/minutes/32625-5724.htm_ Accessed 29 May 2008

Clarke-Farr P.C. Presbyopia: refractive error or the result

5. of the normal ageing process of the eye. S Afr Optom 2004 63 30-35.

Grosvenor T. Primary Care Optometry-Anomalies of Re6. fraction and Binocular Vision. $3^{\text {rd }}$ Edition. Maryland: Butterworth-Heinemann, 1996.

Reidy A, Minassian DC, Vafidis G, Joseph J, Farrow S, Wu

7. J, Desai P and Connolly A. Prevalence of serious eye disease and visual impairment in a north London population: population based, cross sectional study. Brit Med J 1998 316 1643-1646.

8. Mason P. The role of nutrition in cataract development: A review of the literature. Optom Prac 20045 163-171.

9. Korean Medical Database: Prevalence of refractive error and nutrient intake status in a community study. http://kmbase.medric.or.kr/Main.aspx?d=KMBASE\&m=VIEW\&i= 0665220000130050425 Accessed 17 January 2008.

10. McCarty CA and Taylor HR. A review of the epidemiologic evidence linking ultraviolet radiation and cataracts. In: Progress in Lens and Cataract Research: Developments in Ophthalmology. 2002 21-31. Basel: Karger.

11. Griffiths PG. A surfeit of screening? Personal View. British Medical Journal 1997315318.

12. Fraser S, Bunce C, Wormald R and Brunner R. Deprivation and late presentation of glaucoma: a case-control study. Brit Med J 2001322 639-643.

13. McKay R, McCarty CA, and Taylor HR. Diabetic retinopathy in Victoria, Australia: the Visual Impairment Project. Brit Med J Ophthalmol 200084 865-870.

14. Rani PK, Raman R, Sharma V, Mahuli SV, Tarigopala A, Sudhir RR, Kumaramanickavel G and Sharma T. Analysis of a comprehensive diabetic retinopathy screening model for rural and urban diabetics in developing countries. Brit Med J Ophthalmol 200791 1425-1429.

15. Society for Endocrinology, Metabolism and Diabetes of South Africa (SEMDSA). http://www.semdsa.org.za/prevalencedata.htm Accessed 21 December 2007.

16. Kvarnström G, Jakobsson P and Lennerstrand G. Visual 
screening of Swedish children: an ophthalmological evaluation. Acta Ophthalmologica Scandinavia 2001 79(3) 240244(5).

17. Karti KJD. Prevalence of amblyopia in ametropias in a clinical set-up. Kathmandu University Medical Journal 2006 4(16) 470-473.

18. du Toit R, Ramke J and Brian G. Tolerance to prism induced by readymade spectacles: setting and using a standard. Optom Vis Sci 200784 1053-1059.

19. Outline of the Council for Medical Schemes Annual Report for 2006-7. http://www.hst.org.za/healthstats/159/data Retrieved on 21 December 2007.

20. Kriel SJ. Professional Board for Optometry and Dispensing Opticians. Health Professions Council of South Africa. Personal Communication. 1 December 2003.

21. Hoppe E and Frankel R. Optometrists as key providers in the prevention and early detection of malignancies. Optometry 200677 397-404.

22. Weale RA. On the age-related prevalence of anisometropia. Ophthalmic Res 200234 389-392.

23. Luo BP, Brown GC, Luo SC and Brown MM. The quality of life associated with presbyopia. A J Ophthalmol 2008 145 618-622.

24. The Australian Government. Medicare Australia. http:// www.medicareaustralia.gov.au/ Accessed 31 May 2008.

25. RSA (Republic of South Africa). 1974. Health Professions Act, 1974. Cape Town: Government Printer.

26. Herse P. An ophthalmic survey of African patients presenting at rural eye clinics in South Africa. Opt Vis Sci 1991 68(9) 738-742 